\title{
Experience of Patients with Obesity in Contacts with Medical Professionals [Response to Letter]
}

This article was published in the following Dove Press journal:

Patient Preference and Adherence

\section{Krzysztof Sobczak (D) \\ Katarzyna Leoniuk (D) \\ Agata Rudnik (D) ${ }^{2}$}

'Department of Sociology of Medicine \& Social Pathology, Medical University of Gdansk, Gdansk, Poland; ${ }^{2}$ Institute of Psychology, University of Gdansk, Gdansk, Poland
Correspondence: Krzysztof Sobczak Medical University of Gdansk, Department of Sociology of Medicine \& Social Pathology, Tuwima 15, 80-210, Gdańsk, Poland

Tel +48 $58349 \quad 12 \quad 16$

Fax +48 583491249

Email krzysztof.sobczak@gumed.edu.pl

\section{Dear editor}

We would like to thank you for your interest in our article and the opportunity to respond to the issues raised in the comments by Ikotun et al. ${ }^{1}$

Quantitative research methods are used, inter alia, to recognize the frequency of the phenomenon presented in the study. As a result, we can analyze the dependencies and relationships that exist between variables. Therefore, while carrying out the study on the experiences of Polish patients with obesity, we decided to use the quantitative method to explore their contacts with medical professionals. ${ }^{2}$ The adopted research technique (CAWI) consisted of completing a digitized questionnaire by an anonymous respondents via the internet. This method of carrying out research was dictated by several assumptions. Notably, we need to point out obtaining high-quality data based on a large group of respondents. Online research provides this possibility, in particular, by eliminating the total presence and research pressure when filling in the survey. This results in greater honesty of respondents, especially in situations that are difficult or embarrassing for them. Research using the CAWI technique ensures a sense of anonymity and comfort of participation (choice of time and place), which translates into greater accuracy of the answers. One of the most important advantages of this technique is also reaching a wide group of respondents. ${ }^{3}$ As a disadvantage, we should undoubtedly mention the lack of representativeness, which means that the conclusions cannot be generalized. ${ }^{4}$ We emphasized this fact by describing the limitations of our study, informing that the revealed overrepresentations could have influenced the assessment of the behavior of health professionals. Ethnic origin has not been analyzed by us due to the relatively heteronomous nature of the population in Poland. On the other hand, the comment regarding the determination of socioeconomic status from our colleagues is beneficial and will be taken into account by us in future research. It is worth explaining that in creating the category for the question in Table 2, we used the data collected by the Social Ombudsman for People with Obesity. These were complaints that came from patients with descriptions of specific situations taking place in medical institutions.

Being aware of the advantages and limitations of various research methods, we decided to conduct a purely quantitative study. The suggestion of our colleagues related to the inclusion of patients' narratives as the research tool is extremely valuable. However, it should be borne in mind that in surveys dedicated to numerous groups of respondents, the obtained answers to open-ended questions are characterized by great diversity and relatively low efficiency. Interpretation of 
the answers collected in this way is burdened with linguistic and cultural limitations as well as the risk of misinterpretation. The analysis of the narratives entails limitations related to the participants of the study themselves. In fact, the preference is given primarily to those individuals who have an appropriate level of insight into themselves, and who use a sufficiently rich vocabulary that will allow them to express both emotions and motivations and will enable sharing their experience. This type of research is an excellent tool supporting quantitative methods, and indeed in the future it would be worth enriching our study with eg, interpretative phenomenological analysis (IPA) carried out on a targeted group of patients. ${ }^{5}$

\section{Disclosure}

The authors report no conflicts of interest in this communication.

\section{References}

1. Ikotun O, Lee EWC. Comments on - experiences of obese polish patients when interacting with healthcare professionals [Letter]. Patient Prefer Adherence. 2020;14:1861-1862. doi:10.2147/PPA. S283721

2. Sobczak K, Leoniuk K, Rudnik A. Experience of Polish Patients with Obesity in Contacts with Medical Professionals. Patient Prefer and Adherence. 2020;14:1683-1688. doi.10.2147/PPA.S270704

3. Siuda P. Internet survey: advantages and disadvantages - recapitulation. In: Siuda P, ed. [in Polish] Online research methods. Bydgoszcz: Katedra; 2016:pp.28-81.

4. Best SJ, Krueger B, Hubbard C, Smith A. An Assessment of the Generalizability of Internet Surveys. Social Science Computer Review. 2001;19(2):131-145. doi.10.1177/089443930101900201

5. Smith JA, Flowers P, Larkin M. Interpretative Phenomenological Analysis: Theory, Method and Research. Los Angeles: Sage; 2009.

Dove Medical Press encourages responsible, free and frank academic debate. The content of the Patient Preference and Adherence 'letters to the editor' section does not necessarily represent the views of Dove Medical Press, its officers, agents, employees, related entities or the Patient Preference and Adherence editors. While all reasonable steps have been taken to confirm the content of each letter, Dove Medical Press accepts no liability in respect of the content of any letter, nor is it responsible for the content and accuracy of any letter to the editor.

\section{Publish your work in this journal}

Patient Preference and Adherence is an international, peer-reviewed, open access journal that focusing on the growing importance of patient preference and adherence throughout the therapeutic continuum. Patient satisfaction, acceptability, quality of life, compliance, persistence and their role in developing new therapeutic modalities and compounds to optimize clinical outcomes for existing disease states are major areas of interest for the journal. This journal has been accepted for indexing on PubMed Central. The manuscript management system is completely online and includes a very quick and fair peer-review system, which is all easy to use. Visit http:// www.dovepress.com/testimonials.php to read real quotes from published authors. 